\title{
CONTROLLED TRIAL OF INFLUENZA VACCINE
}

\author{
BY \\ P. B. COOK \\ From the Medical Department, British Petroleum Company Limited, London
}

(RECEIVED FOR PUBLICATION JANUARY 29, 1965)

\begin{abstract}
The employees of an oil company in southern England participated in the controlled trial of a saline polyvalent influenza vaccine. Of 981 volunteers, 681 received the vaccine and the remainder an indistinguishable inert control substance. The identity of the latter group was not disclosed until the incidence of influenza had been assessed. Three questionnaires were circulated in December 1963, February and April 1964 for this purpose.

Local reactions were significantly more marked in the group which received the vaccine. The pattern of any general reaction did not vary between the groups. Unpleasant reactions would not therefore contra-indicate the use of the vaccine. The year 1963/4 was not an epidemic year for influenza, but the incidence of sporadic cases was similar in the two groups. The severity of the illness, as judged by loss of working time, did not vary between the groups. Inoculation in previous years conferred no additional immunity.

This trial suggests that the expense, in terms of time and money, of preventive influenza inoculation is not justified with this preparation. The results might have been different in the presence of an epidemic.
\end{abstract}

Published results concerning the value of influenza vaccines in general are equivocal. The more recent publications, at least so far as industrial groups are concerned, are not supportive. There are two persisting objections; any immunity produced is shortlived, and there is no guarantee that the vaccine used will possess a similar antigenic structure to that of the virus causing any future epidemic. Further study is essential to meet the needs of both the group and the individual at special risk because of other disease.

\section{Method}

Inoculation against influenza on a voluntary basis has been available to members of the staff of the company concerned for the past few years. A double-blind trial of the vaccine was planned in order to assess its value. Although a control group makes demands on the volunteers available it has the great advantage of allowing the subjective reports of local and general reactions to be seen in perspective and is really essential for trials of this kind. It also compensates for the fact that participants may seek inoculation because they are convinced of its efficacy. This attitude may itself produce inac- curacies in assessing the incidence of influenza.

In the autumn of 1963 the usual notice was sent to employees concerning the inoculation programme but it was stated that an inert, harmless substance would be given to a proportion of those requesting the injection in order to assess the merits of the vaccine. The identity of this group would be unknown to the doctor and to the participants until the results had been assessed. A total of 981 employees co-operated in the experiment, received an injection, and completed the questionnaires in the following winter. They were drawn from the offices of the company in the City of London and from the Research Department at Sunbury-on-Thames. The number of defaulters was small (five persons who left the company and were not traced).

\section{The Vaccine}

A polyvalent saline vaccine* was used in a dosage of $1 \mathrm{ml}$. subcutaneously. The inert control injection was identical in appearance and presentation. Each participant was inoculated during October 1963.

\footnotetext{
* Flugen, manufactured by Beecham Research Ltd.
} 


\section{Diagnosis}

Questionnaires were circulated in December 1963, February and April 1964. The December questionnaire posed questions concerning the local and general effects of the inoculation and also the incidence of attacks of influenza. Further enquiries were made concerning specific symptoms (headache, cough, sore throat, sweating, muscle pains, and fever). Questions were also asked concerning loss of working time and the incidence of colds. The questionnaires distributed in February and April omitted questions concerning local and general reactions but were otherwise similar.

If the subject recorded an attack of influenza, and if this was associated with the presence of three or more of the listed symptoms, this was scored as an attack of influenza. If the subject denied influenza but admitted to a cold and noted four or more of the symptoms, this was also scored as an attack of influenza. This method would detect all cases of influenza, and any bias towards over-sensitivity would be similar in the vaccinated and control groups and would not vitiate the results. The definitive diagnosis of influenza remains unsatisfactory without laboratory control, and this was impracticable.

\section{Validity of the Control Group}

Participants were allocated to the control group at random. The controls numbered 300 of the total 981 subjects. Analysis by sex and age group (Table 1) shows an acceptable random distribution between the groups, as does the allocation between the London office and the Research Department.

TABLE 1

COMPARISON OF SEX AND AGE STRUCTURE OF CONTROL AND PROTECTED GROUPS

\begin{tabular}{|c|c|c|c|c|}
\hline & \multicolumn{2}{|c|}{ Control Group } & \multicolumn{2}{|c|}{ Protected Group } \\
\hline & No. & $\%$ & No. & $\%$ \\
\hline $\begin{array}{l}\text { Male } \\
\text { Female }\end{array}$ & $\begin{array}{r}216 \\
84\end{array}$ & $\begin{array}{l}72 \\
28\end{array}$ & $\begin{array}{l}526 \\
155\end{array}$ & $\begin{array}{l}77 \\
23\end{array}$ \\
\hline Total & 300 & 100 & 681 & 100 \\
\hline $\begin{array}{l}\text { Age (yrs.) } \\
\text { Under 25 } \\
26-40 \\
\text { Over } 40\end{array}$ & $\begin{array}{r}69 \\
119 \\
112\end{array}$ & $\begin{array}{l}23 \\
40 \\
37\end{array}$ & $\begin{array}{l}150 \\
285 \\
246\end{array}$ & $\begin{array}{l}22 \\
42 \\
36\end{array}$ \\
\hline Total & 300 & 100 & 681 & 100 \\
\hline
\end{tabular}

\section{Local and General Effects of the Inoculation}

All those receiving an inoculation of either vaccine or control substance were asked to record
TABLE 2

SUBJECTIVE DESCRIPTION OF LOCAL AND GENERAL EFFECTS OF INOCULATION

\begin{tabular}{|c|c|c|c|c|}
\hline & \multicolumn{2}{|c|}{ Control Group } & \multicolumn{2}{|c|}{ Protected Group } \\
\hline & No. & $\%$ & No. & $\%$ \\
\hline $\begin{array}{l}\text { Local reaction } \\
\text { None } \\
\text { Slight } \\
\text { Considerable }\end{array}$ & $\begin{array}{r}168 \\
123 \\
9\end{array}$ & $\begin{array}{r}56 \\
41 \\
3\end{array}$ & $\begin{array}{r}320 \\
338 \\
23\end{array}$ & $\begin{array}{r}47 \\
50 \\
3\end{array}$ \\
\hline Total & 300 & 100 & 681 & 100 \\
\hline $\begin{array}{l}\text { General reaction } \\
\text { None } \\
\text { Slight } \\
\text { Considerable }\end{array}$ & $\begin{array}{r}248 \\
43 \\
9\end{array}$ & $\begin{array}{r}83 \\
14 \\
3\end{array}$ & $\begin{array}{r}539 \\
121 \\
21\end{array}$ & $\begin{array}{r}79 \\
18 \\
3\end{array}$ \\
\hline Total & 300 & 100 & 681 & 100 \\
\hline
\end{tabular}

the local and general subjective effects in one of three simple terms. The results are shown in Table 2.

There were significantly more local reactions in the protected group than in the controls $\left(\chi^{2}=6 \cdot 79\right.$; $\mathbf{P}<0.01)$. Slightly more general reactions are reported in the protected group but the difference is not significant $\left(\chi^{2}=1 \cdot 6 ; \mathbf{P}=0 \cdot 2\right)$. Systemic disturbance does not appear to be a factor of importance in the use of the vaccine so far as this trial discloses.

\section{Incidence of Influenza}

Table 3 shows the incidence of influenza in the two groups. The number of attacks recorded in the control group was equivalent to an incidence of $14 \%$ throughout the winter. The corresponding figure for the vaccinated group was $15 \%$. The vaccine conferred no protection in the year under review.

Although the protection provided by the vaccine is thought to be of short duration, it was conceivable that previous inoculation against influenza might have been a significant factor. This problem

TABLE 3

INCIDENCE OF INFLUENZA AND DETAILS OF TIME LOST BY CONTROL AND PROTECTED GROUPS

\begin{tabular}{|c|c|c|c|}
\hline & $\begin{array}{l}\text { Control } \\
\text { Group }\end{array}$ & $\begin{array}{l}\text { Protected } \\
\text { Group }\end{array}$ & Total \\
\hline No. in group & 300 & 681 & 981 \\
\hline $\begin{array}{l}\text { Attacks of influenza } \\
\text { Attack rate }(\%)\end{array}$ & $\begin{array}{l}42 \\
14\end{array}$ & $\begin{array}{r}104 \\
15\end{array}$ & $\begin{array}{r}146 \\
15\end{array}$ \\
\hline $\begin{array}{l}\text { No. causing loss of time } \\
\text { Total man-days lost } \\
\text { Range (days) } \\
\text { Average time lost per attack } \\
\text { (days) }\end{array}$ & $\begin{array}{l}25 \\
127 \\
1-19 \\
3 \cdot 0\end{array}$ & $\begin{array}{l}81 \\
388 \\
1-21 \\
3 \cdot 7\end{array}$ & $\begin{array}{r}106 \\
515 \\
3 \cdot 5\end{array}$ \\
\hline $\begin{array}{l}\text { Attacks between October and } \\
\text { December } 1963 \\
\text { Attacks between December and } \\
\text { February } 1964 \\
\text { Attacks between February and } \\
\text { April } 1964\end{array}$ & $\begin{array}{r}7 \\
25 \\
10\end{array}$ & $\begin{array}{l}29 \\
48 \\
27\end{array}$ & $\begin{array}{l}36 \\
73 \\
37\end{array}$ \\
\hline
\end{tabular}


was studied in the vaccinated group. Of 681 individuals, 508 had been inoculated previously. Seventy-nine attacks were recorded in this larger group, equivalent to an attack rate of $15.5 \%$. In the smaller group of 173 who were inoculated for the first time, 25 cases of influenza occurred, equivalent to an attack rate of $14.5 \%$. This provides no evidence that previous inoculation was a factor of importance.

\section{Lost Working Time}

This aspect was explored by recording the number of working days lost where a diagnosis of influenza had been made from the replies to the questionnaire. The results appear in Table 3. The severity of attacks, as judged by the amount of working time lost, is uninfluenced by the vaccine.

The anticipated increased incidence of influenza in winter is apparent (Table 3). The figures do not suggest that the vaccine exerted any protective influence limited to the short period immediately following administration. The proportion of attacks of influenza which occurred early in the winter is greater in the protected group than in the control group.

\section{Discussion}

These results are disappointing. Considerable financial expenditure and loss of working time result from the inoculation programme. From this single study it appears that no practical benefit accrues so far as sporadic cases of influenza are concerned.

Published reports of trials with various influenza vaccines are equivocal. Davenport (1962) summarized several trials supporting the value of inoculation but the degree of protection varied widely and was often low. The Medical Research Council Committee on Influenza and Other Respiratory Virus Vaccines (1958) reported similar findings. Some of these reports concerned years when the incidence of influenza in the control group was less than $10 \%$. This suggests that success has not been limited to years in which major epidemics occur. Other writers (Meichen, Rogan, and Howell, 1962; Richardson and Kilpatrick, 1964) have failed to demonstrate any value from the vaccine. Howell and Stott (1964), using an oil adjuvant vaccine, could not report any protection but stressed that their trial concerned a year in which an epidemic did not occur.

Whatever the benefits conferred by inoculation, they are of short duration (Himmelweit, 1963) and probably significant only in those years when influenza epidemics occur. There is no guarantee that future epidemics will be caused by organisms of similar antigenic structure to those used in the manufacture of the vaccine. Because of these factors, chemotherapy may ultimately prove to be a more profitable field for research. Further efforts in influenza prevention are indicated to meet the needs of population groups and also the 'high-risk' patient with other disease.

In the type of community concerned with this trial, emphasis must be placed on the importance of an adequate control group. When a vaccination programme has been operating for some years there remains a phalanx of volunteers who are conscious proponents of the value of vaccination and often subconsciously very biased witnesses. The use of an inert control substance compensates for this error and allows a comparison of local and general effects of inoculation between the two groups. It is noteworthy that a few subjects in the control group noted severe reactions to the injection of the control substance.

A double-blind trial of a polyvalent influenza vaccine has yielded nothing to support the value of inoculation in the year under review.

Beecham Research Limited have been most cooperative and supplied the control injections.

I am grateful to Dr. A. Anderson, Chief Medical Officer to the British Petroleum Company Limited, for his active encouragement and for permission to publish.

\section{REFERENCES}

Davenport, F. M. (1962). J. Amer. med. Ass., 182, 11.
Himmelweit, F. (1963). Brit. J. clin. Pract., 17, 661.
Howell, R. W., and Stott, A. N. B. (1964). Brit. J. industr. Med.,
21, 259.
Medical Research Council Committee on Influenza and Other Res-
piratory Virus Vaccines (1958). Brit. med. J., 1, 415.
Meichen, F. W., Rogan, E., and Howell, R. W. (1962). Brit. J.
industr. Med., 19,203.
Richardson, I. M., and Kilpatrick, S. J. (1964). Med. Offr, 111, 5. 